\title{
Study to Investigate Learning Motivation Factors Within Formal and Informal Learning Environments and Their Influence upon Web-Based Learning
}

\author{
doi:10.3991/ijet.v5i4.1338 \\ Sadia Riaz, Dayang Rohaya Awang Rambli, Rohani Salleh, Arif Mushtaq \\ Universiti Teknologi PETRONAS, Tronoh, Malaysia
}

\begin{abstract}
Learning is a cognitive process that occurs either in a formal or informal learning environment, by way of adopting either formal or informal learning process. While the significance of former has been widely accepted, later is still researched and lacks relevant studies on its implications for web-based learning, especially by way of instigating learning motivation. This paper presents descriptive analysis of learning motivation factors within (i) formal and informal learning environments, and (ii) formal and informal learning processes, and then examines their influence on web-based learning by computing Pearson correlations. To achieve study objectives, the paper discusses relevant literature and then conceptualizes a research model to be tested through a survey based questionnaire. Formal learning process is discussed with reference to learning activities as promoted by formal learning institutes, while informal learning process is examined by way of investigating learning motivation factors associated with (i) video-games, (ii) social networking websites and (iii) motion-pictures. Results illustrate interesting revelation of learning motivational factors, particularly motivational factors associated with informal learning environment and processes have been found to have a statistically significant relationship with web-based learning. The paper concludes implications of the statistical findings for designing of cognitively engaging web-based learning environments.
\end{abstract}

Index Terms-Formal Learning Process, Informal Learning Process, Web-Based Learning, Learning Motivation Factors

\section{INTRODUCTION}

A process is an activity which takes place over time and has a precise aim with respect to results to be achieved [1]. Similarly, like any other process, learning is also a process [2] which is inspired by different progressions that take place in our brain. The learning process, however, either takes place formally or informally. Formal Learning, as the name suggests, is regarded as formal form of education which is provided by training institutions, while informal learning takes place outside dedicated learning environment and there is some doubt as to whether the notion of informal learning is the most useful way forward. Coffield [3] argues that informal learning also needs to be seen as fundamental, necessary and valuable in its own right, which at times unswervingly supports in finding employment.
Within any learning process, how interaction takes place is important because not only does it affects the learning effectiveness, but also learner's motivation; as pointed out by Schuemer [4], "to be a successful learner, learners must have a high degree of motivation”. Motivation to learn is strength of desire or a learning temperament that varies from one learner to another and in the real world learners are motivated differently due to variety of cognitive and psychological factors influencing different learning environment. Therefore, in this paper, our research focus is to investigate motivational factors that govern two learning environments namely; formal and informal; by way of interacting with learners through their respective processes, and to study their relationship with web-based learning.

\section{LITERATURE REVIEW}

This section provides a review of the literature deemed relevant to the research objectives.

\section{A. Formal and Informal Learning Environments}

Learning environments are said to be constructivist in nature and primarily responsible for keeping learners adequately engaged by providing sufficient resources. The four main components of a learning environment are (a) an enabling context, (b) resources, (c) a set of tools, and (d) scaffolds [5]. Thus, a learning environment, either formal or informal is responsible for providing resources to optimize learning. In case of formal learning process, educational institutes or corporate organizations are responsible to ensure adequate infrastructure is in place. While an informal learning environment is the one supported by a number of socio-economic, family and cultural factors. In this paper we are examining formal and informal learning environments in context of their respective learning processes. This is because learning occurs in response to cognitive processes performed by human brain [6] and the extent to which effective learning occurs again varies from person to person and depends upon learners' mental capacities as well as on socio-cognitive and environmental circumstances.

\section{1) Formal Learning Process}

Formal learning process is more planned in characteristics and results from activities that are held within a structured learning setting. Australian Education Council [7] defines formal learning as: "learning typically pro- 
vided by education or training institutions". It is organized and well-executed in terms of learning objectives and also leads to certification at the end. Thus, formal learning is a part of formal education system, which is institutionalized and aims at providing knowledge as per a designed curriculum. It is carried out mostly with a specific place, time, theme, subject and goal.

\section{2) Informal Learning Process}

Informal learning process ([7], [8]) on the contrary, occurs outside a dedicated learning environment and as a result of activities and interests of individuals and groups. There is no widely-accepted or recognized definition of informal learning, however, according to Organization for Economic Corporation \& Development [9] informal learning results from "carrying out daily-work, family and leisure related activities". Therefore, contemporary understanding of informal learning is that it happens outside formal education system and does not lead to a certified qualification [10].

Conlon [11] believes that informal learning tends to be the outcome of incidental learning through everyday experience. For example, surfing on the internet, indulging in online socializing activities, using different ICTs devices \& multimedia applications, exploring and enlarging experiences by enjoying flexibility to perform multiple tasks are all related to self-directed learning. Moreover, it is interesting to note that learners may not necessarily be aware of their learning experience in an informal learning environment because it is a learning process while not being aware of it.

Within informal learning process, leisure or entertainment activities are of special interest for us because measuring the rationale behind behavior of people, for doing what they are doing, is a difficult task. However, at the same time having an understanding of why people choose to participate in leisure or entertainment activities could help in explaining motivational factors behind, as there are no obvious external forces compelling people to perform leisure activities [12]. Leisure activities are described as non-work activities that are freely chosen without compulsion to participate or without any prospects of rewards.

Leisure activities can be either active or passive in nature and learners can participate from playing physical sports to participating in social activities and from watching television to playing games on the internet. The question is, if these activities have any motivational impact, positive or negative on learning? To answer this question, we have narrowed down our research focus on computer or video-games, social networking websites and motionpictures.

- Computer or Video-Games: Researchers have found out that informal activities such as computer games provide instructive benefits and there is substantiate evidence that video-games may not motivate the players intrinsically, but learners may be motivated to use them for learning purposes [13]. Thus, computer and video games have a strong role in today's media-rich world. This role has been acknowledged by researchers in the past [14] which is present in informal learning by way of simulations, role plays and quizzes. Computer and video games offer a virtual play environment and follow set of instructions to make players abide by the game rules. It engages player by way of goal-setting, challenges, interaction, story-telling and feed-back mechanism [15].

- Social Networking Websites: Pedagogical institutions have resisted to the temptation and ever growing influence of social networking websites on learners and have considered them to be repulsive in nature. Until recently, the same institutions had to accept the significance of collaborative development and sharing which is the main characteristic of social networking websites and has enchanted the younger generation [16].

- Motion Pictures: A motion picture projects a series of still pictures on the celluloid screen so as to create a world of visual illusion and to engage viewer's neural and cognitive processes [17]. Likewise, moviemakers spend millions of dollars to use formal and narrative devices for acquiring and depicting creativity in their movies by way of accurate timing of cuts, framing content in a shot, the placement of objects in scene, directions to actors, music sound and dialogs for narrating a story to viewers [18] The purpose is to affect viewers emotionally and leave memorable mark on their minds. Researchers have found out that different genres of movies, for example historical or period dramas, or science fictions can instigate productive discussion, enable intelligent questioning on part of learners and enhance their visual processing and imaginations, thus motivating them to learn [19].

\section{B. Learning Motivation}

Motivation is an emotion or a sense of feeling that captivates positive senses in our brain by employing extrinsic and intrinsic factors. This eventually is responsible for stimulating learning process. Today researchers are increasingly interested in finding out factors that are critical for enhancing or preventing learners' involvement in a learning environment [20] and one such factor is motivation. Learning is found to be the most effective when an individual is ready to learn, or in other words, when one wants to know something, without any compulsion or extrinsic rewards. Therefore, study of motivation in informal learning environments and processes is fundamental for this study.

Motivation theorists assume that all learned activities or behaviors occur due to learning motivation. It is said that "a learned behavior will not occur unless it is energized" [21]. At the same time, motivation remains a major area of concern among psychologists [22] who continue to probe into the question; "whether motivation is a primary or secondary influence on behavior?" Psychological research also distinguishes between intrinsic and extrinsic motivation. Intrinsic motivation reflects activities undertaken by individuals for their own sake or for personal interest. This means intrinsic motivation is what is felt by an individual, when he/she is inspired by his/her own attitudes, skills, and interests. Extrinsic motivation, on the contrary, reflects activities undertaken for instrumental assessment or external reasons [23]. Motivation, in short, energizes our behavior to achieve our set goals [24].

Weller [25] suggests that learning environment is useful in determining focus of the student's attention and on what needs to be learned. Therefore, an effective learning environment would be the one that promotes learning atmosphere, and favorable attitudes towards learning, and at the same time, provides high levels of self-efficacy and self-motivation [26]. Learning Motivation has been found 
to be the best predictor of student achievement in a study that investigated factors influencing student achievement in learning Japanese language through the medium of satellite television [27].

In a web-based environment, motivation has a phenomenal impact on the entire learning process. Research has also shown that unless learners are not intrinsically motivated, they are likely to have less constructive experiences when interacting with e-learning systems [28]. Therefore, it is a fact now that learning motivation plays an important role in web-based learning environment and at time has accounted for more than one fourth of student achievements, as reported by researchers at Iowa State University [29].

Unfortunately, within the study of instructional designing learning motivation is often overlooked without realizing its core significance [30]. Any sophisticatedly designed learning program or system either face-to-face or web-based, will eventually fail, if learners are not motivated to learn. Zvacek [30] argues to explore aspects of instructional designing, beyond the cognitive domain while Kurse [31] states that "without a desire to learn on part of the student, retention is unlikely..." It is, therefore, up to instructional designers to deliberate upon this issue on a more serious note and strive to enhance learning motivation in learners, so they can master new skills and transfer those skills back into their working environment [32].

After discussing significance of learning motivation for web-based learning environments, we may now examine learning motivation theories that are used in designing of research constructs for the questionnaire.

- Moshinskie's Learning Motivation Framework: As discussed earlier, motivation is like a catalyst that triggers learning process and research has proven that when students are intrinsically motivated, they learn more effectively. To support this argument, motivational framework deemed relevant to our questionnaire is Moshinskie's learning motivation framework [33]. Moshinskie has identified two types of learners; one with active behavior and second with passive behavior towards learning. The active learners require very little extrinsic motivation because they are intrinsically enough motivated to perform learning tasks. While the passive learners are required to be pushed at every stage of learning process, as they seriously lack intrinsic motivation and need more extrinsic motivation. Moshinskie’s model for learning motivation, therefore, depends heavily on collaborative approaches for making learning effective and this framework is useful in designing research constructs for formal learning environment and process.

- Malone \& Lepper's Motivation Theory: This theory provides valuable insight to motivational factors that are exclusively associated with interactive learning in a multimedia based environment [34]. According to this theory; Challenge, Curiosity, Control \& Fantasy are the four important aspects required for ensuring cognitive involvement of learners when they are exposed to a multimedia based learning environment ([35],[36]).

\section{RELATED STUDIES}

Internationally, substantial research has been carried out to investigate motivational factors associated with formal learning environments, including web-based learning. For instance, Hanrahan [20] conducted a survey on the effect of learning environment factors on students' motivation and learning. Wai-Ching Poon and colleagues [37] conducted a study on Web-based learning (WBL) environment in eight Malaysian universities and Tsai [38] conducted a survey by developing a CILES-S scale to investigate student preferences and learning motivation factors towards Internet-based learning environments. However, all the above referred studies have reconfirmed the importance of motivation for learning environments and focused primarily on formal learning environments, including web-based learning.

Given the situation that highlights the gap in the literature with regards to investigating motivational factors associated with formal and informal learning environments, and their influence upon web-based learning, this is an important research area which has not been adequately covered in existing studies. And to cover this research gap, following research model is to be tested.

\section{ReseARCH Model AND Hypothesis}

Based on literature review, the following hypothesis is to be tested as per the research model shown in figure 1 .

\section{A. Hypothesis}

H1: Learning motivation factors of a formal learning environment positively influence on web-based learning.

H2: Learning motivation factors of a formal learning process positively influence on web-based learning.

H3: Learning motivation factors of an informal learning environment have no influence on web-based learning (null-hypothesis).

H4: Learning motivation factors for informal learning processes have no influence on web-based learning (null-hypothesis).

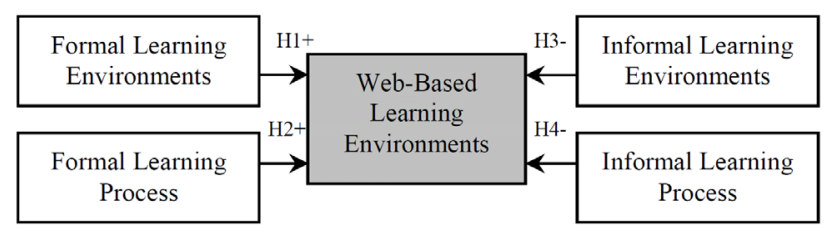

Figure 1. Research Model

\section{B. Research Constructs}

The main and sub-constructs for our questionnaire were developed after carrying out extensive literature review (Table I).

Each construct included questions presented in a fivepoint Likert mode, ranging from "strongly agree" to “strongly disagree.” Respondents' responses were scored as: for the "strongly agree" response was assigned a score of 5, while for the "strongly disagree" response was assigned a score of 1 . Consequently, students gaining higher scores in a certain scale showed stronger preferences toward the specific scale.

\section{DATA ANALYSIS \& FINDINGS}

\section{A. Sample}

The questionnaire was distributed to a total number of 650 students enrolled currently in Pakistan based Mohammad Ali Jinnah University and Malaysia based Universiti Teknologi PETRONAS. Majority of the respondents (78\%) belonged to the department of computer 
TABLE I.

MAIN AND SUB-RESEARCH CONSTRUCTS

\section{Formal Learning Environment}

Access to technology and infrastructure, collaborative learning environment, working flexibility, policy \& regulations, management information system, enabling learning environment.

\section{Informal Learning Environment}

Learning flexibility, socio-economic conditions, affordable infrastructure, privacy \& concentration, ownership, encouraging policies, cultural values, societal pressure, extrinsic motivation (family pressure).

\section{Formal Learning Process}

Collaborative development \& sharing environment, mastering skills (technical, critical, problem-solving, transferable), realistic learning approach, extrinsic motivation, self-efficacy, intrinsic motivation, presence of instructor, better assessment, improved concentration, effective feedback mechanism.

\begin{tabular}{|l|l|}
\hline \multicolumn{2}{|c|}{ Informal Learning Process } \\
\hline Video Games & $\begin{array}{l}\text { Self-regulated environment, advance thinking } \\
\text { skills, enjoyment and pleasure, intense involve- } \\
\text { ment, problem-solving skills, interactivity, } \\
\text { winning satisfaction, goal setting, outcomes and } \\
\text { feedback }\end{array}$ \\
\hline $\begin{array}{l}\text { Social Net- } \\
\text { working Web- } \\
\text { sites }\end{array}$ & $\begin{array}{l}\text { Intrinsically enjoyable, sense of real participa- } \\
\text { tion, no extrinsic compulsion, blogging, creating } \\
\text { and sharing virtual objects, special interest news, } \\
\text { participating in collaborative projects, download- } \\
\text { ing (music, videos etc.), cognitive absorption }\end{array}$ \\
\hline $\begin{array}{l}\text { Motion Pic- } \\
\text { tures }\end{array}$ & $\begin{array}{l}\text { Well-executed shots, story \& narration, adaptive } \\
\text { visual flow, music cognition, special effect } \\
\text { sequences, emotionally binding }\end{array}$ \\
\hline \multicolumn{2}{|c|}{ Web-Based Learning } \\
\hline $\begin{array}{l}\text { Ease of use, interactivity, privacy \& data storage, collaborative devel- } \\
\text { opment, effective assessment, responsive feedback, content manage- } \\
\text { ment, critical judgment, navigation system, multimedia components, } \\
\text { visual cognition, user control system }\end{array}$
\end{tabular}

and information sciences or IT department of their respective Universities, with sufficient knowledge and background of web-based learning environments and formal \& informal learning processes. The response rate of the questionnaire was 75 percent (487) of which, 473 responses were usable, as most items were adequately answered.

\section{B. Reliability Analysis}

The reliability analysis of the entire construct was computed, followed by the assessment of individual items measuring the 5 main constructs and 3 sub-constructs (Table II). Cronbach's alpha indicates how well a set of items (or variables) measures a single uni-dimensional latent construct. Cronbach's alpha is usually low, if the data has multidimensional structures.

All research variables exceeded the acceptable standard of reliability analysis of 0.70 [39]. These statistical results confirmed that the measurement scales used in this study met the acceptable standard of reliability and rather attained a high level of reliability.

\section{Descriptive Analysis of Learning Motivation Factors Associated with Formal \& Informal Learning Environments, and Formal \& Informal Learning Processes.}

Motivational Factors for Formal Learning Environment (Table III): Access to technology \& infrastructure factor received the highest mean score of 3.58 indicating
TABLE II.

Cronbach's Alpha SCORE OF MAIN AND Sub-CONSTRUCTS

\begin{tabular}{|lc|}
\hline \multicolumn{1}{|c|}{ Main Construct } & Alpha $(\boldsymbol{\alpha})$ \\
\hline Formal Learning Environment & 0.81 \\
\hline Formal Learning Process & 0.73 \\
\hline Informal Learning Environment & 0.71 \\
\hline Informal Learning Process & 0.74 \\
\hline Sub Construct - Video Games & 0.78 \\
\hline Sub Construct - Social Networking Websites & 0.71 \\
\hline Sub Construct - Motion Pictures & 0.74 \\
\hline Web-based Learning Environment & 0.82 \\
\hline
\end{tabular}

TABLE III.

MEAN OF FORMAL LEARNING ENVIRONMENT MOTIVATIONAL FACTORS

\begin{tabular}{|lc|}
\hline \multicolumn{1}{|c|}{ Motivational Factors } & Mean \\
\hline Access to technology and infrastructure & 3.59 \\
\hline Collaborative learning environment & 3.10 \\
\hline Working flexibility & 2.86 \\
\hline Policy \& regulations & 3.38 \\
\hline Management information system & 3.48 \\
\hline Enabling learning environment & 3.30 \\
\hline Scale Mean Score: 3.30 & \\
\hline $\begin{array}{l}\text { Note: Means are determined by using a five-point Likert scale, from } \\
\text { strongly disagree (1) to strongly agree (5) }\end{array}$ \\
\hline
\end{tabular}

that learning motivation is directly effected by basic infrastructure, resource support and facilities provided by the institution or organization. This includes learners' adequate access to computers, internet and provision of efficient internet speed, hardware and software support etc.

This is followed by management's information systems which received second highest mean score of 3.48 suggesting that learning motivation is cultivated by the environment. If practice of good governance is adopted at the top level, and efficient management information systems (with adequate ICTs) are included to provide learning support systems than learners will experience enhanced learning motivation.

Institutional policy and regulations also impact upon learning motivation. This factor received the third highest mean score of 3.38, indicating restrictions such as on content downloading, installation of software, and lab access after campus hours or on weekends are all major learning motivation turn-offs. The initiatives taken by the institutions for creating an enabling learning environment also promote learning motivation among students (fourth highest mean score of 3.30). This is followed by learning motivation induced by collaborative learning environment (mean score 3.10).

Motivational Factors for Informal Learning Environment (Table IV): The learning flexibility factor within informal learning environments received the highest mean score of 3.67. This suggests flexibility of learning 'anywhere, anytime' is a major learning initiator. This is particularly true in case of web-based learning environments. The reason associated could be that learners experience more of intrinsic motivation when they enjoy learning flexibility. This may be judged from the statistical fact that factor extrinsic motivation received the lowest mean score of 2.53 , justifying our claim that learning 
process, especially the self-directed one, is hindered under pressure of any type either it comes from family or from the institutions. Extrinsic motivation is regarded as unfavorable as it tends to create doubt and anxiety in the learning process. Unfavorable beliefs like these impede the learning process because they direct the learners' attention away from the learning activity itself, focusing it instead on their low ability.

Furthermore, societal pressure factor is also closely related to extrinsic motivation, as it is imposed by the community on learners. This factor also received a relatively low mean score of 2.77 followed by the factor cultural values which obtained a relatively higher mean score of 3.21 than the factor societal pressure. This suggests cultural norms and values, although a part of extrinsic motivation plays a significantly decisive role in formation of a conducive learning environment and in determining of learning activities uptake.

The prevailing socio-economic conditions also impact upon learning motivation as this factor received a notable second highest mean score of 3.44 followed by factor affordable infrastructure with third highest mean score of 3.41 because availability and affordability of infrastructure and learning facilities promote learning environment. Similarly, ownership factor received mean score of 3.30 indicating that if infrastructure is affordable and its ownership is within the means, it will surely promote learning motivation among learners.

Motivational Factors for Formal Learning Process (Table V): The motivational factors that govern formal learning process obtained the highest scale mean score of 3.52. This suggests learners' highest level of preferences for formal learning processes.

Motivational factor collaborative development \& sharing environment received the highest mean score of 3.85, suggesting that respondents felt it creates a positive impact on classroom interaction and at the same time promotes group-thinking. This also true in case of web-based learning environment as it extensively applies collaborative learning tools (e.g. email, message boards, real-time chat, and audio-video conferencing) that can motivate learning by promoting collaborative development, sharing and group-thinking among learners.

The motivation to master skills received the second highest mean score of 3.72. This suggests that learning motivation is elicited, if learners' believe their technical, problem-solving, transferable and critical skills will be enhanced and bring an overall improvement in their expertise. In other words, learners who believe that they will never be able to complete the task successfully are the once who no longer perceive a link between their actions and positive outcomes. Therefore, consideration may be given to such psychological aspects in instructional designing of learning environments where perceptions and actions of the learners are given due considerations in order to make them experience the world in new ways [40].

The factor realistic learning approach is perceptional is nature, as it suggests respondents think formal learning process is more practical or sensible. This factor received the third highest mean score of 3.69. Our argument to this statistical finding is that learners perceive formal learning process to be more realistic when comparing with informal learning because they may not conveniently know
TABLE IV.

MEAN OF INFORMAL LEARNING ENVIRONMENT MOTIVATIONAL FACTORS

\begin{tabular}{|ll|}
\hline \multicolumn{1}{|c|}{ Motivational Factors } & Mean \\
\hline Learning flexibility & 3.67 \\
\hline Socio-economic conditions & 3.44 \\
\hline Affordable infrastructure & 3.41 \\
\hline Privacy \& Concentration & 3.37 \\
\hline Ownership & 3.30 \\
\hline Encouraging policies & 3.28 \\
\hline Cultural values & 3.21 \\
\hline Societal pressure & 2.77 \\
\hline Extrinsic motivation (family pressure) & 2.53 \\
\hline Scale Mean Score: 3.22 & \\
\hline $\begin{array}{l}\text { Note: } \text { Means are determined by using a five-point Likert scale, from } \\
\text { strongly disagree (1) to strongly agree (5) }\end{array}$ \\
\hline
\end{tabular}

TABLE V.

MEAN of Formal LEARNING PROCEss Motivational FACTORS

\begin{tabular}{|lc|}
\hline \multicolumn{1}{|c|}{ Motivational Factors } & Mean \\
\hline Collaborative development \& sharing environment & 3.85 \\
\hline Mastering skills (technical, critical, problem-solving etc.) & 3.72 \\
\hline Realistic learning approach & 3.69 \\
\hline Extrinsic motivation & 3.64 \\
\hline Self-efficacy & 3.51 \\
\hline Intrinsic motivation & 3.47 \\
\hline Presence of instructors & 3.42 \\
\hline Better assessment & 3.36 \\
\hline Improved concentration & 3.32 \\
\hline Effective feedback mechanism & 3.26 \\
\hline Scale Mean Score: 3.52 & \\
\hline $\begin{array}{l}\text { Note: Means are determined by using a five-point Likert scale, from } \\
\text { strongly disagree (1) to strongly agree (5) }\end{array}$ \\
\hline
\end{tabular}

what to ask for unless they are not exposed to the true potential of informal learning process and environment [41].

Similarly, extrinsic motivation (appraisal, reward, punishment) within formal learning received a notable fourth highest mean score of 3.64, while the same factor received the lowest mean score of 2.53 in informal learning environments. The rational behind is that formal learning process takes place in a dedicated learning environment, follows a strict schedule, assessment and reporting. Therefore, psychologically learners feel under pressure to perform better both individually and also from their peers due to constant comparisons. This aspect tends to diminish in an informal learning setup and becomes a major learning motivation turn-off. On the contrary, factors associated with intrinsic motivation within the formal learning process received the mean score of 3.47 which is particularly lesser than that of extrinsic motivation factors within the same process. As per Moshinskie's model for learning motivation, an activity is intrinsically motivating if external rewards, pressure and appraisal are not necessary for learners to initiate and continue that activity. This suggests that extrinsic motivational factors have a comparatively imperative role in formal learning process because learners crave for performance appraisal. The other side of this finding is that intrinsic motivation is 
comparatively less significant in a formal learning process, which may ultimately lead to mental anxiety and learning frustration among learners. This may eventually pave the way to poor performance and cognitive disengagement of learners in a learning environment.

The motivational factor self-efficacy received the fifth highest mean score of 3.51 ascertaining the fact that if learners have higher self-efficacy beliefs or opinions about themselves in relation to performing a learning task they are likely to experience enhanced learning motivation. For example, during formal learning process if learning activities are designed creatively using constructed models, simulations, visual graphics, and videos, then not only the subject-related performance of the students will improve due to higher concentration or attention level but at the same time they will experience self efficacy.

Presence of instructor factor promotes learning motivation due to the presence-of-mind effect and also has extrinsic motivation characteristics. This factor received a moderate high mean score of 3.42. It is because learners are compelled to experience learning motivation when actual demonstration takes place right in front of their eyes. This aspect is missing in an informal learning setting. However in case of web-based learning this effect can be attained by keeping learners cognitively engaged through web-based instructions, content material, learning activities and tasks.

Motivational Factors for Informal Learning Process (Table VI): Informal learning process was extensively covered in the questionnaire and three sub-sections were exclusively designed and dedicated to motivation factors associated with learning from (i) video-games, (ii) social networking web-sites and (iii) motion-pictures.

Video-Games: Being 'in control' as suggested by Malone \& Lepper's motivational theory makes a learning environment fascinating and captivating, that is why factor self-regulated environment received the highest mean score of 3.78. This is because self-regulated learning revolves around strategies for performing active mental processes, and video-games are designed as such to keep players actively engaged and in control of the situation.

This is followed by a very closely related factor intense involvement, second highest mean score 3.63. Intense involvement indicates the extent to which players are able to relate and engage themselves in a playing environment. This involvement also leads to the development of personal association with the characters in game, due to interactive simulations of the game play. That is why factor interactivity has received the third highest mean score 3.61. This also indicates Malone \& Lepper's motivational component fantasy is an influential technique which miraculously works in simulation-based learning environments.

Video games are designed with clear-set defined objectives. This is for players to set targets for themselves and to be more passionately involved in the game-play. The motivation factor goal setting received a notable fourth highest mean score of 3.52, suggesting that learning occurs more passionately if the objectives of the study are precisely defined and well-executed within the instructional designing of learning environment.
TABLE VI.

MEAN of InFormal LEARNING PROCEss Motivational FACTORS

\begin{tabular}{|c|c|}
\hline Motivational Factors & Mean \\
\hline \multicolumn{2}{|l|}{ Video Games } \\
\hline Self-regulated environment & 3.78 \\
\hline Advance thinking skills & 3.43 \\
\hline Enjoyment and pleasure & 3.47 \\
\hline Intense involvement & 3.63 \\
\hline Problem-solving skills & 3.41 \\
\hline Interactivity & 3.61 \\
\hline Winning satisfaction & 3.09 \\
\hline Goal setting & 3.52 \\
\hline Outcomes and feedback & 3.20 \\
\hline \multicolumn{2}{|l|}{ Scale Mean Score: 3.46} \\
\hline \multicolumn{2}{|l|}{ Social Networking Websites } \\
\hline Intrinsically enjoyable & 3.79 \\
\hline Sense of real participation & 3.56 \\
\hline No extrinsic compulsion & 3.26 \\
\hline Blogging & 3.31 \\
\hline Creating and sharing virtual objects & 3.63 \\
\hline Special interest news & 3.09 \\
\hline Participating in collaborative projects & 3.74 \\
\hline Downloading (music, videos etc.) & 3.22 \\
\hline Cognitive absorption & 3.81 \\
\hline \multicolumn{2}{|l|}{ Scale Mean Score: 3.49} \\
\hline \multicolumn{2}{|l|}{ Motion Pictures } \\
\hline Well-executed shots & 3.37 \\
\hline Story \& narration & 3.40 \\
\hline Adaptive visual flow & 3.62 \\
\hline Music cognition & 3.30 \\
\hline Special effect sequences & 3.25 \\
\hline Emotional bonding & 3.22 \\
\hline \multicolumn{2}{|l|}{ Scale Mean Score: 3.36} \\
\hline $\begin{array}{l}\text { Note: Means are determined by using } \\
\text { strongly disagree (1) to strongly agree }\end{array}$ & cale, from \\
\hline
\end{tabular}

The motivation factor enjoyment and pleasure (fifth highest mean score 3.47 ) is psychological in nature and is related to the fun and amusement part of the games which is generated by way of including curiosity and challenge components in the games, as suggested by Malone \& Lepper.

Games which are either action-packed or strategy oriented, inculcate traits of planning and execution in players and tend to promote learning motivation by way of advance thinking skills (mean score 3.43). This factor has been very closely followed by factor problem-solving skills (mean score 3.41). This is also in line with Malone \& Lepper's motivational theory where component challenge suggests that activities must not be either too easy or too difficult.

Social Networking Websites: The factor cognitive absorption obtained the highest mean score of 3.81, as social networking websites have become very effective for establishing relationships in social context. Learners engage themselves in socializing activities due to intrin- 
sic motivation that is why this factor received second highest mean score of 3.79. The motivation factor, participating in collaborative projects received the third highest mean score of 3.74. This indicates that virtual or online communities, support learning by way of collaborative development and sharing, which is also one of the key motivators in formal learning environments. This is further justified from the statistical fact that factor creating and sharing virtual objects has attained a notable third highest mean score of 3.63. Factor sense of real participation received fourth highest mean score of 3.56 . This indicates, online virtual communities provide engagement with realistic task approach and participants feel they are actually performing activities, for example when leaving comments, updating statuses, uploading pictures, participating in discussions or blogging.

Motion Pictures: The factor, adaptive visual flow obtained the highest mean score of 3.62. This indicates that viewers tend to lose viewing attention when over-lapping or poorly-edited displays are presented to them. This is an important factor which in technical terms refers to the visual momentum created by motion-pictures. Visual Momentum is a designing technique used for cognitively integrating information across displays [42]. This is followed by factor story or narration (second highest mean score 3.40). Movies tend to keep viewers engaged by way of adaptive visual screen play and narration. This factor technically refers to effectiveness of script which is in the form of speech and video.

The next factor gaining third highest mean score is well-executed shots (mean score 3.37). This refers to effective framing of content in a shot. This is also suggestive that in order to grab visual attention of viewers, effective designing and placement of the content is very critical.

Music makes motion-pictures a great treat for our sensory senses especially emotions, and the factor Music Cognition received a notable fourth highest mean score of 3.30. This suggests that background music, songs and musical effects, which vary as per the requirements of the scene, make motion pictures cognitively engaging for viewers.

The special effect sequences received a mean score of 3.25 slightly higher than the factor emotional bonding mean score 3.22. The special effect sequences are thought-provoking and at times make viewers sit at the edge of their seats when they are being executed on the big screen. These special effect sequences are created by way of simulation and generating curiosity which is again in line with Malone \& Lepper's motivational framework.

Motivational Factors for Web-Based Learning (Table VII): Respondents indicated high inclination towards the motivational factors that encourage web-based learning, as the total average mean score of all the factors is above the value of 3 .

The motivational factor content management received the highest mean score of 3.78 followed by the factor navigation system (second highest mean score 3.73). This indicates that learning friendly navigation system tend to make web-based learning motivating because it makes browsing, and searching a lot more easier. Learners can quickly access the information desired and manage their content for learning purposes.
TABLE VII.

MEAN OF Web-BASEd LEARNING ENVIRONMENT MotivationaL FACTORS

\begin{tabular}{|lc|}
\hline \multicolumn{1}{|c|}{ Motivational Factors } & Mean \\
\hline Ease of use & 3.02 \\
\hline Interactivity & 3.69 \\
\hline Privacy \& data storage & 3.43 \\
\hline Collaborative development & 3.57 \\
\hline Effective assessment & 3.46 \\
\hline Responsive feedback & 3.63 \\
\hline Content management & 3.78 \\
\hline Critical judgment & 3.48 \\
\hline Navigation system & 3.73 \\
\hline Multimedia components & 3.13 \\
\hline Visual cognition & 3.67 \\
\hline User control system & 3.52 \\
\hline Scale Mean Score: 3.51 & \\
\hline
\end{tabular}

The factor interactivity received third highest mean score of 3.69, suggesting that appliance of methodologies such as drill, hypermedia, simulation, games, tools etc. make web-based learning interactive and indulges learners in the learning process by way of motivation them. This factor is very closely followed by factor visual cognition which received fourth highest mean score of 3.67. Visual cognition is related to the visual layout of the webbased learning environment and how it tends to instigate learning motivation.

The factor responsive feedback obtained moderately high mean score of 3.63 (fifth highest). This is an important factor, as it also distinguishes face-to-face learning from web-based learning. The factor collaborative development received a mean score of 3.57 ascertaining the fact that learning becomes more interactive, fun and exciting when it occurs not only through material or content but also through community of participating learners using chat, threaded discussion, whiteboards etc. Learning motivation occurs when students are able to engage themselves in discussions on diverse topics with facilitators and peers.

The factor user controls obtained mean score of 3.52 followed by the factor critical judgment mean score of 3.48. This indicates that learners are inclined towards making sense of novel learning situations in a web-based learning environment by referring to their motivational beliefs. Motivational beliefs refer to the opinions, judgments and reflective thinking of the learners on or about objects, events or subject-matter domains.

It is interesting to note that factor ease of use obtained relatively a low mean score of 3.02. This indicates learners are moderately less motivated by the usage ease of web-based learning environments. The reason may be that if learners are adequately and cognitively kept engaged by web-based learning environment, then issues concerning usage-complexity of the learning environment are of lesser importance to them. 


\section{Hypothesis Testing}

H1: Learning motivation factors for formal learning environment positively influence on web-based learning.

It has been found out that learning motivation factors influence upon web-based learning, as the relationship has been found to be significant at $\mathrm{p}<0.01$ level, with $\mathrm{r}=$ 0.280 . Hence the research hypothesis is accepted.

H2: Learning motivation factors of a formal learning process positively influence on web-based learning.

The result indicates that learning motivation factors for formal learning process have a statistically significant relationship with web-based learning at $\mathrm{p}<0.01$ level, with $r=0.505$. Hence the research hypothesis is accepted.

H3: Learning motivation factors for informal learning environment have no influence on web-based learning (null-hypothesis).

The correlation coefficient between learning motivation factors for informal learning environment has been found to have a statistically significant relationship with web-based learning at $p<0.05$ level, with $r=0.149$. Therefore, null-hypothesis is rejected.

H4: Learning motivation factors for informal learning processes have no influence on web-based learning (null-hypothesis).

The correlation coefficient between learning motivation factors for informal learning processes have been found to have a statistically significant relationship with web-based learning at $\mathrm{p}<0.01$ level, with $\mathrm{r}=0.408$. Therefore, null-hypothesis is rejected.

TABLE VIII.

PEARSON CORRELATION COEFFICIENTS BETWEEN WEB-BASED LEARNING AND MOTIVATIONAL FACTORS FOR FORMAL AND INFORMAL LEARNING ENVIRONMENTS AND PROCESSES

\begin{tabular}{|lcc|}
\hline \multicolumn{1}{|c}{ Factors } & $\begin{array}{c}\text { Web-Based Learn- } \\
\text { ing (WBL), r }\end{array}$ & $\begin{array}{c}\text { Significance } \\
\text { (two tailed) }\end{array}$ \\
\hline Formal Learning Environment & 0.280 & $0.000 * *$ \\
\hline Formal Learning Process & 0.505 & $0.000 * *$ \\
\hline $\begin{array}{l}\text { Informal Learning Environ- } \\
\text { ment }\end{array}$ & 0.149 & $0.020 *$ \\
\hline Informal Learning Process & 0.408 & $0.002 * *$ \\
\hline $\begin{array}{l}* * \text { denotes significance at the p }<0.01 \\
* \text { denotes significance at the p }<0.05 \\
\text { Note: Means are determined by using a five-point Likert scale, from } \\
\text { strongly disagree (1) to strongly agree (5) }\end{array}$ \\
\hline
\end{tabular}

\section{CONCLUSION}

In order to motivate learners for taking active part in any learning process, either formal or informal, authentic contexts are indispensable. And to help learners understand intricate problems and subject matters, extensive resources are required, which are provided by formal and informal learning environments. Our first research objective was to investigate motivation factors associated with these (a) environments, in terms of providing resources to learners and (b) processes, in terms of making them efficient learners.

The study concludes that factors such as provision of technology and infrastructure, management information systems, enabling and collaborative learning environment are prevalent motivational factors that inspire learning motivation in formal learning environments, such as educational institutions or corporate organizations. While, factors such as learning flexibility, socio-economic conditions, affordable infrastructure, privacy \& concentration, ownership, and cultural values are leading factors that inspire motivation in an informal learning environment. Similarly, within formal learning process, respondents indicated their highest inclination towards learning motivation factors such as collaborative development \& sharing, extrinsic motivation, mastering skills and selfefficacy. While within informal learning processes the motivational aspects of self regulated learning, advance thinking skills, enjoyment and pleasure, participation in collaborative projects, cognitive absorption, adaptive visual flow, visual and musical cognition were the toprated factors that inspired learning motivation within informal learning processes. Another important finding of this study was that extrinsic motivation is a powerful learning promoter in a formal learning setup. While within informal learning setup, extrinsic motivation tends to lose its impact and intrinsic motivational factors become better motivators for learning.

Our second research objective was to investigate influence of learning motivation factors, as identified in research objective 1 , on web-based learning. This objective was achieved by way of computing Pearson correlation coefficients. The study concludes that motivational factors associated with formal learning environments and process positively influence upon web-based learning. As for informal learning environments and processes, it was hypothesized that motivational factors associated with them have no influence on web-based learning (nullhypothesis). However our results showed that motivational factors associated with informal learning environment and processes have a statistically significant relationship with web-based learning, thus rejecting the null hypothesis.

This, therefore, indicates that learning is no longer a stagnant process, which used to be dependent on predetermined conditions earlier. It has rather adopted a more vibrant mode and can occur under any environment, provided learners are able to engage themselves constructively for building their knowledge base. Informal learning is predominantly lead by intrinsic motivational factors, as there are no obvious compulsions on learners to perform learning activities in an informal learning setup. The study therefore concludes that informal learning processes have implications for designing of cognitively engaging web-based learning environments. For example, learning motivation factors associated with social networking websites tend to promote networking by way of informal socializing activities. Networking is also an important aspect of web-based learning environment and it can occur by way of interacting with experts, bloggers, peers and limitless sources of information online. Likewise, when learners contribute to online discussions and message boards, they are involved in an active learning process where they realize importance of making valuable contribution which is viewed by relatively a larger number of online communities, thus making them responsible learners too.

Similarly in motion pictures, visual flow of information followed by narration or story telling keeps the viewers cognitively engaged. Especially when the story is 
reproduced in conjunction with auditory and visual mechanics, the viewers are fully absorbed in the screen-play. This aspect of motion-pictures has implications for webbased learning environments by way of improving designing techniques for sustaining visual momentum. Similarly in motion pictures framing of scenes indicate framing of content in scenes. This approach is related to the concept of closure in designing of interfaces and can be useful in designing of content for multimedia based instructional material. By implementing the concept of closure and progressive disclosure, learners will not be over-whelmed by the amount of information presented to them and will be in a position to organize information as per their learning interests.

Video-games are ideally suited for designing of selfregulated environments, which is also an important aspect of web-based learning. The said environment becomes self-regulated by way of incorporating learning motivation factors such as challenge, control, fantasy and curiosity as suggested by Malone and Lepper in their framework.

This study, therefore, concludes learning motivation factors for informal learning environment and processes are equally significant for designing of cognitively engaging web-based learning environments, as they tend to provide a more creative medium for engaging learners and have tendencies to incorporate imaginative and creative innovations in designing of web-based learning environments.

\section{REFERENCES}

[1] Kronlöf, K. (1993). Method Integration, Concepts and Case Studies. Wiley, Chichester, England.

[2] Smith, M. K. (1999). Learning Theory, the encyclopedia of informal education. Available online: www.infed.org/biblio/blearn.htm

[3] Coffield, F. (2000). The Necessity of Informal Learning. Bristol: The Policy Press.

[4] Sankaran, S. R. and Bui, T. (2001). Impact of Learning Strategies and Motivation on Performance: A Study in Web-Based Instruction. Journal of Instructional Psychology, Vol. 8, pp. 191-201.

[5] Hannafin, M.J., Land, S. and Oliver, K. (1999). Open Learning Environments: Foundations, methods, and models. In C. Reigeluth (Ed), Instructional-design theories and models (Volume II). Mahwah, NJ: Erlbaum.

[6] Jesan, J. P. and Lauro, D. M. (2003). Human Brain and Neural Network Behavior: A Comparison. Ubiquity, Vol. 4, Issue 37.

[7] Wynes, S. H. and Francesca. (2009). At a Glance: Informal learning. National Centre for Vocational Education Research. Available online: http://www.ncver.edu.au/research/proj/nd08022.pdf

[8] Jeffs, T. and Smith, M. K. (2005). Informal Education. Conversation, democracy and learning. Ticknall: Education Now. Available online: http://www.infed.org/i-intro.htm

[9] OECD. (2005). The role of the national qualifications system in promoting lifelong learning: Report from thematic group 2Standards and quality assurance in qualifications with special reference to the recognition of non-formal and informal learning. pp. 5. Available online: http://www.oecd.org/dataoecd/57/27/3437 6318.pdf.

[10] Richardson, S. (2004). Employers' contribution to training. NCVER, Adelaide.

[11] Conlon, T. (2003). A review of informal learning literature, theory and implications for practice in developing global professional competence. Journal of European Industrial Training, Vol. 28, No 2/3/4/, pp. 283-95.

[12] Hayes, A. M. (2004). The Understanding of Motivations, Preferences and Constraints of Recreation in a Rural Costa Rican Community: La Zona De Monteverde. Available online: http://etd.fcla.edu/UF/UFE0003302/hayes_a.pdf
[13] Whitton, N. (2007). Motivation and computer game based learning. Education \& Social Research Institute, Manchester Metropolitan University.

[14] Gibson, D. C., Aldrich, and Prensky, M. (2007). Games and simulations in online learning: research and development frameworks. Information Science Publishing, Hershey, PA.

[15] Prensky, M. (2001). Why Games Engage Us? Digital Game-Based Learning, New York: McGraw-Hill.

[16] Derossi (Ed.). (2007). Online Social Networking And Education: Study Reports On New Generations Social And Creative Interconnected Lifestyles, Nov. 9. Available online: http://www.masternewmedia.org/

[17] Zacks, J. M. and Magliano, J. P. (in press) Film, Narrative, and Cognitive Neuroscience. To appear in: Art \& the Senses, ed. D. P. Melcher and F. Bacci. New York: Oxford University Press.

[18] Bordwell, D. and Thompson K. (2003). Film Art: An Introduction. (Seventh edition ed.). New York: McGraw-Hill.

[19] Ontell, V. (2004). Science Fiction as a Learning Motivation. Community \& Junior College Libraries, Volume 12, Issue 1, pp. 57 - 70. Available Online: http://www.informaworld.com/smpp/

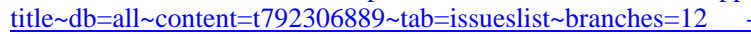
v12

[20] Hanrahan, M. (1998). The effect of learning environment factors on students' motivation and learning. International Journal of Science Education, Vol. 20, No 6, pp. 737-753. doi:10.1080/ $\underline{0950069980200609}$

[21] Abd-el-fattah, S. M. (2006). The implicit theories of intelligence: A review of Carol Dweck's motivation process mode. International Education Journal, Vol. 7, No. 4, pp. 547-554.

[22] Huitt, W. (2001). Motivation to learn: An overview, Educational Psychology Interactive. Valdosta State University. Available online: http://www.edpsycinteractive.org/col/motivation/motivate. $\underline{\mathrm{html}}$

[23] Reinholt, M. (2006). No More Polarization, Please! Towards a More Nuanced Perspective on Motivation in Organization. SMG Working Paper, No. 9, ISBN: 87-91815-26-6.

[24] Weiner, B. (1990). History of motivational research in education. Journal of Educational Psychology, Vol. 82, No 4, pp. 616-622. doi:10.1037/0022-0663.82.4.616

[25] Weller, M. (2005), General Principles of Motivation. Los Angeles Business Journal. Available online: http://honolulu.hawaii.edu/ intranet/committees/FacDevCom/guidebk/teachtip/motivate.htm

[26] Kubanyiova, M. (2006). Developing a Motivational Teaching Practice in EFL Teachers in Slovakia: Challenges of Promoting Teacher Change in EFL Contexts. TESL-TJ, Vol. 10, No 2.

[27] Roberts, T. G. and Dyer, J. E. (2005). The influence of learning styles on student attitudes and achievement when an illustrated web lecture is used in an online learning environment. Journal of Agricultural Education, Vol. 46, No. 2.

[28] Lanzilotti, R. Montinaro, F. and Ardito, C. (2009). Influence of students' motivation on their experience with E-Learning systems: An experimental study. Springer-Verlag Berlin Heidelberg, Universal Access in HCI, Part III, LNCS 5616, pp. 63-72.

[29] SHIH, C-C. (2001). Web-Based Learning: Relationships among student motivation, attitude, learning styles, and achievement. Journal of Agricultural Education, Vol. 42, Issue 4.

[30] Zvacek, S. M. (1991). Effective Affective Design for Distance Education. Springer Boston, Vol. 36, No. 1, DOI 10.1007/BF02761286, pp. 40-43.

[31] Kurse, K. (2004). The benefits and drawbacks of e-learning. Available Online: http://www.e-learningguru.com/articles/art1 3.htm

[32] Lee, K. (2005). E-learning, the quest for effectiveness. Malaysian Online Journal of Instructional Technology, Vol. 2, No 2, pp. 6171, ISSN: 1823-1144.

[33] Smith, R. (2008). Running head: Motivational Factors in ELearning. George Washington University. Available online: www.discreate.org/ruthcsmith/GWU\%20Papers/Motivation.pdf

[34] Malone, T. W. and Lepper, M.R. (1987). Making learning fun: taxonomy of intrinsic motivations for learning. In Snow, R.E. and Farr, M.J. (Eds.). Aptitude, Learning and Instruction III: Cognitive and Affective Process Analyses. Hillsdale, N.J, Erlbaum. 
[35] Den boe, W. W. (2008). Game Development Using Game Design Patterns, Serious Games and the Clima Futura Project. Available online: $\quad$ www.math.vu.nl/ eliens/archive/student/.../scriptiewouter-25-11-08.pdf

[36] Schaller, D. (2005). What Makes a Learning Game?. Available online: http://www.eduweb.com/schaller-games.pdf

[37] Poon, W-C., Low, K., F. L-T., and Yong, D. G. (2004). A study of Web-based learning (WBL) environment in Malaysia. The International Journal of Educational Management, Vol. 18, No. 6, pp. 374-385. doi:10.1108/09513540410554031

[38] Tsai, C.-C. (2005). Preferences toward Internet-based Learning Environments: High School Students, Perspectives for Science Learning. Educational Technology \& Society, Vol. 8, No. 2, pp. 203-213.

[39] Nunnally, J.C. and Bernstein, I. H. (1994). Psychometric Theory (3rd Ed.). New York: McGraw-Hill.

[40] Gee, J.P. (2003). What video games have to teach us about learning and literacy. New York: Palgrave Macmillan, pp. 3.

[41] Mushtaq, A., Sulaiman, S., and Loviscach J. (2010). Issues with Flexibility; A reason for not using online reservation systems?. $4^{\text {th }}$ International Symposium on Information Technology, proceedings ITSIM ‘10, Kuala Lumpur Convention Center, Kuala Lumpur, Malaysia.

[42] Neale, W. C. and Kursted, P. (1994). The development of an interactive multimedia courseware program highlighting visual momentum. CHI Conference Companion, pp. 19-20.

\section{AUTHORS}

Sadia Riaz has received her MBA (IT) degree in 2002 from Muhammad Ali Jinnah University Islamabad, Pakistan. She is associated with Ministry of Investment, Government of Pakistan in capacity of Deputy Director and has an extensive research and report writing experience. At present she is pursuing doctorate studies in Computer and Information Sciences from Universiti Teknologi PETRONAS, Malaysia. Her area of research is integration of media psychology for designing of cognitively engaging web-based learning environments (email: missriaz@yahoo.com).

Dr. Dayang Rohaya Awang Rambli is currently a senior lecturer at the Computer and Information Science Department, Universiti Teknologi PETRONAS, Malaysia. She received her BS from University of Nebraska, M.Sc from Western Michigan University, USA, and Ph.D from Loughborough University, UK (email: roharam@petronas.com.my)

Dr. Rohani Bt. Salleh is a Senior Lecturer in the Department of Management and Humanities, Universiti Teknologi PETRONAS. She has done M.A (HRM) from Hull University, UK and later received her PhD in HRM from Leeds University, UK (email: rohanisalleh@petronas.com.my)

Arif Mushtaq received his MS (Digital Media) degree in 2006 from Hochschule Bremen, Germany. At present he is pursuing doctorate studies in Computer and Information Sciences from Universiti Teknologi PETRONAS, Malaysia. His area of research is flexible reservation systems (email: coolafee@yahoo.com).

Submitted June $6^{\text {th }}, 2010$. Published as resubmitted by the authors October 30 2010. 